\title{
Structural evidence for kinetic and thermal stability changes of $\alpha$-amylase due to exposure to [emim][lactate] ionic liquid
}

https://doi.org/10.1515/tjb-2019-0270

Received June 18, 2019; accepted July 15, 2020;

published online November 12, 2020

\section{Abstract}

Objectives: $\alpha$-amylases hydrolyze $\alpha-1,4$ glycosidic bonds in starch. ILs used as co-solvent in different enzymatic reactions to improve activity, selectivity and stability of enzymes. In this study, fluorescence spectroscopy method was used to explain the effect of [emim] [lactate] on kinetic and thermal stability of Aspergillus oryzae $\alpha$-amylase.

Methods: Effect of different concentrations of [emim] [lactate] on activity of $\alpha$-amylases was determined. Kinetic parameters, optimum $\mathrm{pH}$ and temperature and thermal stability were determined and compared with absence of [emim][lactate]. Intrinsic fluorescence spectroscopy for Trp residues was performed for both presence and absence of [emim][lactate].

Results: Activity of $\alpha$-amylase decreases in presence of [emim][Lac]. Moreover, $\mathrm{Km}$ of $\alpha$-amylase in the presence of [emim][lactate] increases while Vm decreased. Optimum temperature in presence of [emim] [lactate] increases from 45 to $50{ }^{\circ} \mathrm{C}$ while optimum $\mathrm{pH}$ decreases from 9 to 7 . Thermal stability of $\alpha$-amylase in the presence of [emim] [lactate] is similar to that in the absence of [emim][lactate] at 40 and $50{ }^{\circ} \mathrm{C}$ but decreases at $60^{\circ} \mathrm{C}$. Intrinsic fluorescence spectroscopy shows unfolding of native structure of $\alpha$-amylase is dependent on [emim][lactate] concentration. Conclusions: Presence of [emim][lactate] ionic liquid as co-solvent leads to structural unfolding of $\alpha$-amylase and loss of its activity and thermal stability.

*Corresponding author: Dr. Mehdi Ebrahimi, Department of Biochemistry and Biophysics, Faculty of Biological Sciences, VaraminPishva Branch, Islamic Azad University, Varamin, Iran, Phone: +9821 367250 10, E-mail: ebrahimi@iauvaramin.ac.ir. https://orcid.org/ 0000-0001-7656-3879

Tina Akhavan and Azadeh Hekmat, Department of Biochemistry, Faculty of Basic Science, Science and Research Branch, Islamic Azad University, Tehran, Iran
Keywords: $\alpha$-amylase; ionic liquids; 1-ethyl-3-methylimidazolium L-(+)-lactate; fluorescence spectroscopy; structural unfolding.

\section{Introduction}

$\alpha$-amylases (1,4-a-D-glucan glucanohydrolase, EC 3.2.1.1) hydrolase $\alpha-1,4$ glycosidic bonds between $\alpha$-D-glucose units in starch and yield dextrin and monomeric products [1]. $\alpha$-amylases are widely used as an efficient replacement for chemical hydrolyzing methods in starch conversion processes in a broad range of industrial applications such as food, fermentation, paper, and textile [2]. There are growing demands for the use of $\alpha$-amylases in new industrial processes in which the operational conditions are different from the enzyme's native condition. $\alpha$-Amylase is being incorporated into biochemical reactions that produce at high temperatures, and could be substituted for high-cost reactant [3]. Therefore, thermal stability of $\alpha$-amylase is the most important factor affecting the usefulness of this enzyme in the starch liquefaction process at elevated temperature [4, 5]. Different approaches based on the process in demand have been used to improve $\alpha$-amylases properties. These approaches include genetic manipulation, immobilization, and medium engineering.

This is proven that beside the some benefits such as improvements in the solubility of hydrophobic substrates, prevent undesirable water-induced side reactions, and altered enzyme chemistries, using organic cosolvents leads to rapid enzyme inactivation by denaturation, conformational rigidity, or inhibition [6]. Recently, using ionic liquids (ILs) has become an attractive approach for the medium engineering of enzymes. They widely use as green alternatives to conventional organic solvents in pure or buffer mixture systems [7]. ILs are completely composed of ions; they are liquid at or near room temperatures and have excellent chemical/thermal inertness. Physical characteristics (such as melting point, viscosity, density, solubility, and hydrophobicity) and thermal properties of ILs depends on the species of cation and anion as well as the length of 
the alkyl groups on the cation [8,9]. Relatively large asymmetric organic cations and organic or inorganic anions are used to prepare ILs [10]. In comparison to organic solvents, ILs have advantages such as near-zero vapor pressure, thermal stability, and widely tuneable properties [11]. The mentioned unique properties of ILs have facilitated their utilization in chemical synthesis and catalysis, electrochemistry, biomass conversion, fuel production and processing, liquid crystal development, biotransformation, biotechnology and many other fields [12].

ILs dissociate to to their cation and anion in solvent and in addition to the interactions between ILs ions themselves and with solute species, they interact with other molecules that they interface with $[13,14]$. The first place influenced by IL ions is the solvent accessible surface of the enzyme molecule. Interactions in surface area lead to local conformational changes which extend to overall structure of enzyme and change the activity and stability of enzyme $[15,16]$. Therefore, using ILs as cosolvent in many biocatalytic reactions achieving different effects mainly in activity and selectivity [17]. The typical cations in ILs are di-alkyl- $N, N$-imidazolium (alkyl ammonium, alkyl pyridinium and pyrrolidinium) or phosphate imidazolium (alkyl phosphonium) while the typical anions are halides, tetrafluoroborate, and sulfonamides. Due to the promising reports in this field, biochemical properties of different enzymes such as $\beta$-galactosidase [18], alcohol dehydrogenase [19], horseradish peroxidase [20], protease [21], lipase $[22,23]$, luciferase $[24,25]$, and $\alpha$-amylase [10] in the presence of different ILs are investigated. In spite of these and other related studies, there is no agreement between researchers on the mechanism of stability, structural, and kinetic changes in enzymes in the presence of ILs [26].

Therefore, the use of ILs as a part of reaction media in enzyme-catalyzed reactions has attracted interest in recent years. This is the first report that evaluates the activity, stability, kinetic, and structural changes in $\alpha$-amylase from Aspergillus oryzae in the presence of 1-ethyl3-methylimidazolium L-(+)-lactate IL. It is important to know that if ILs physical properties alone lead to alterations in enzyme kinetic and stability or structural changes due to interaction with ILs are also effective.

\section{Materials and methods}

\section{Materials}

$\alpha$-amylase, 1,3-dinitrosalicylic acid has been obtained from Sigma Chemicals Co. Potato starch and 1-ethyl-3-methylimidazolium
L-(+)-lactate are from Sigma-Aldrich. All other chemicals are analytical grade. Solutions were prepared with double-distilled water.

\section{$\alpha$-Amylase assay}

$\alpha$-Amylases activity was determined according to the method developed by Miller (Miller 1959) with some modifications. In this method 3,5-dinitrosalisilic acid reagent was used for reducing sugars released by $\alpha$-amylase. In brief, $0.5 \mathrm{~mL}$ of $\alpha$-amylase enzyme $(1 \mathrm{U} / \mathrm{mL})$ with or without [emim][lactate] were added to $1 \mathrm{~mL}$ of starch solution $(1 \% \mathrm{w} / \mathrm{v}$ in $20 \mathrm{mM}$ sodium phosphate buffer with $6.7 \mathrm{mM}$ sodium chloride, pH 6.9) and mixed by swirling and incubated for $15 \mathrm{~min}$ at $20^{\circ} \mathrm{C}$. Then, $1 \mathrm{~mL}$ of DNS solution ( $96 \mathrm{mM}$ 3,5-dinitrosalicylic acid and $5.3 \mathrm{M}$ sodium potassium tartrate) was added to the mixture and placed in a boiling water bath for $15 \mathrm{~min}$ to stop $\alpha$-amylase activity. Solution were stored on ice for $10 \mathrm{~min}$ and then absorbance in $540 \mathrm{~nm}$ was recorded for sample. In the blank sample, $\alpha$-amylase solution was replaced with the same volume of deionized water. One unit of $\alpha$-amylase activity is defined as the amount of enzyme that releases $1 \mathrm{mM}$ of reducing sugars (with maltose as the standard) per minute under the specified assay conditions.

\section{Determination of kinetic parameters}

The effect of [emim] [lactate] concentration ( 1 and $0.4 \mathrm{M}$ ) on the $\mathrm{Km}$ and $\mathrm{Vm}$ parameters was evaluated by measuring the $\alpha$-amylase activity in different amounts of starch $(2-10 \mathrm{mg} / \mathrm{mL})$ as substrate. The Lineweaver-Burk plot was used to determine $\mathrm{Vm}$ and $\mathrm{Km}$ factors.

\section{Optimum temperature and $\mathrm{pH}$}

The optimum temperature of $A$. oryzae $\alpha$-amylase in the absence and presence of [emim][lactate] was determined by the separate incubation of enzyme and starch solutions for $5 \mathrm{~min}$ at $25-80^{\circ} \mathrm{C}\left(5^{\circ} \mathrm{C}\right.$ intervals). The solutions were then used for $\alpha$-amylase assay.

$\alpha$-amylase solution was prepared in different buffers with the desired $\mathrm{pH}$ (in range of 3-10) to investigate optimum $\mathrm{pH}$. The following buffers were used: glycine- $\mathrm{HCl}$, sodium citrate, sodium acetate, sodium phosphate, and tris- $\mathrm{HCl}$. Then, the $\alpha$-amylase solution with appropriate $\mathrm{pH}$ was used for enzymatic assay in the presence $(0.4 \mathrm{M})$ or absence of [emim][lactate].

\section{Thermal inactivation}

Thermal inactivation of $A$. oryzae $\alpha$-amylase was determined by the incubation of enzyme solution at $40,50,60$, and $70{ }^{\circ} \mathrm{C}$ and was compared with same condition in the presence of $0.4 \mathrm{M}$ of [emim] [lactate]. A-amylase activity of each sample was determined every $5 \mathrm{~min}$ for $20 \mathrm{~min}$. Residual activity against time was used to compare the inactivation profiles.

\section{Fluoresce spectroscopy}

Intrinsic fluorescence of $A$. oryzae $\alpha$-amylase $(0.1 \mathrm{mg} / \mathrm{mL})$ was examined in the absence and presence $(0.2,0.4$, and $1 \mathrm{M})$ of [emim] [lactate] using a Perkin-Elmer fluorescence spectrophotometer apparatus 
(USA). Enzyme samples were incubated for $5 \mathrm{~min}$ at room temperature, and then excited at $295 \mathrm{~nm}$; emission was recorded from 300 to $400 \mathrm{~nm}$. Both excitation and emission slits were set to $5 \mathrm{~nm}$. A blank sample without enzyme was used to remove the background fluorescent effects of imidazolium ring of [emim][lactate]. The final emission spectra resulted from the subtraction of emission of each sample from the blank.

\section{Results and discussion}

\section{Effects of [emim][Lac] on the $\alpha$-amylase activity}

The effect of different concentrations $(0.2-1 \mathrm{M}$ with 0.2 intervals) of [emim] [lactate] on $\alpha$-amylase activity is represented in Figure 1. Relative activity of $\alpha$-amylase shows decreases with increase in [emim][lactate] concentrations. Decrease in $\alpha$-amylase activity in the presence of $0.2 \mathrm{M}$ of [emim][lactate] was inappreciable. But $\alpha$-amylase activity in the presence of $0.4 \mathrm{M}$ of [emim] [lactate] decreased to $60 \%$ compared to that in the absence of IL. The highest decrease (35\% of initial reaction rate) was observed in the presence of $0.8 \mathrm{M}$ of [emim][lactate]. Decrease in the activity of enzymes in aqueous solution containing IL and with increase in IL content is common [10, 25-28]. Sate reports loss in the activity of Candida Antarctica lipase due to aggregation in the presence of [emim] $\left[\mathrm{EtOSO}_{3}\right]$, [emim] $\left[\mathrm{NO}_{3}\right]$ and [emim] $\left[\mathrm{N}(\mathrm{CN})_{2}\right][29]$. Turner also reports [bmim] [cl]-induced inactivation and unfolding of cellulase from Trichoderma reesei [30]. However, in our previous study, the activity of luciferase from Photinus pyralis was observed to increase in the presence of [TMG][Lac] [31].

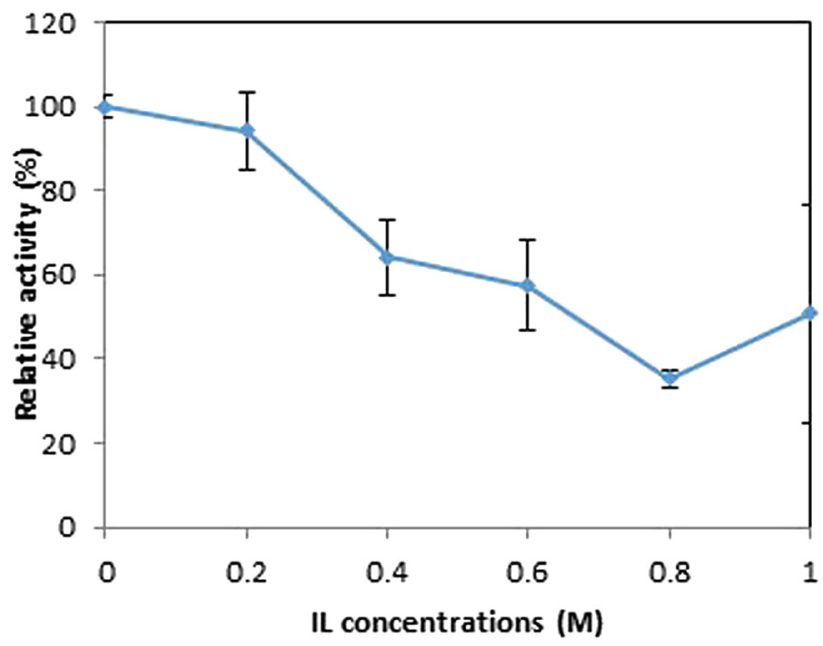

Figure 1: The effect of different concentrations of [emim][Lac] on $\alpha$-amylase activity.
Moreover, H-bonding basicity and nucleophilicity of anionic part of ILs affect the enzyme activity in the presence of ILs [32]. In addition to the anionic part, other factors -including alkyl chain length in cations, IL polarity, viscosity, ion kosmotropicity, amphiphilicity, hydrophobicity, and an IL network-can affect enzyme, medium, and substrate relationship and hence enzyme activity [33]. Comparison of the activity of commercial peroxidase in the presence of five 1-alkyl-3-methylimidazolium-based ILs represent better activity in the presence of ILs with short alkyl chain length [34]. Therefore, there is no general rule to evaluate and predict the changes in the activity of enzymes in the presence of different ILs; hence, these effects should be examined.

\section{Effects of ionic liquid on the kinetic of enzyme}

Michaelis-Menten and Lineweaver-Burk plots were used for the determination of $\mathrm{Vm}$ and $\mathrm{Km}$ of $\alpha$-amylase from $A$. oryzae in the absence and presence of two concentrations (0.4 and $1 \mathrm{M})$ of [emim][lactate]. The hyperbolic curves are the characteristic feature of a true enzyme. The obtained values for $\mathrm{Vm}$ and $\mathrm{Km}$ of $\alpha$-amylase are listed in Table. Km increases from $0.005 \mathrm{M}$ in the absence of [emim] [lactate] to 0.019 and 0.042 in the presence of 0.4 and $1 \mathrm{M}$ of [emim][lactate] respectively. This increase reveals the decrease in affinity and looser substrate binding by enzyme [35]. Unlike $\mathrm{Km}, \mathrm{Vm}$ decreases in the presence of both concentrations compared to the absence of [emim][lactate] (see Table 1).

\section{Optimum temperature and $\mathrm{pH}$ of a-amylase}

The sensitivity of $\alpha$-amylase to temperature $\left(25-80^{\circ} \mathrm{C}\right)$ in the absence and presence of [emim][lactate] $(0.4 \mathrm{M})$ was compared; the results are shown in Figure 2. $\alpha$-amylase activity in the absence of [emim] [lactate] reached its maximum at $45^{\circ} \mathrm{C}$. In light of the fact that $98 \%$ of the activity is at $50^{\circ} \mathrm{C}$, the optimum temperature can be determined at $45-50^{\circ} \mathrm{C}$. In

Table 1: Kinetic parameters of a-amylase from A. oryzae in the absence and presence of [emim][lac].

\begin{tabular}{lrrr}
\hline & 1 M [emim][lac] & 0.4 M [emim][lac] & Without IL \\
\hline Km (M) & 0.042 & 0.019 & 0.005 \\
Vm (U) & 0.032 & 0.078 & 0.118 \\
\hline
\end{tabular}


the presence of [emim][lactate], maximum activity is achieved at $50^{\circ} \mathrm{C}$. According to these results, there is no significant change in the optimum temperature of $\alpha$-amylase in the absence and presence of $\alpha$-amylase.

The $\mathrm{pH}$ profile of $\alpha$-amylase in the presence and absence of [emim] [lactate] is depicted in Figure 3. According to this, the optimum $\mathrm{pH}$ of $\alpha$-amylase decreased from 8.5 in the absence to 7 in the presence of [emim][lactate]. Electrostatic interactions between ionized side chains of amino acid residues play a critical role in the overall structure of proteins and therefore their activity. The ionization state of these residues depends on the $\mathrm{pH}$ of their environment. Therefore, the changes in environmental $\mathrm{pH}$ can change the activity of enzymes. These effects of hydrogen ion concentration on the activity of enzymes have close similarities to the effects of activators and inhibitors. The $\mathrm{pH}$ profile of enzyme activity can yield valuable information on the nature of the kinetic mechanism followed by the enzyme and can help to identify specific groups playing important roles in the reaction [36]. Different factors affecting the $\mathrm{pKa}$ of side chain of residues in proteins, including dehydration (Born effect), charged-charged interactions (Columbic interactions), and charged dipole interactions (hydrogen bonds), are most important [37]. Solvents can change the pKa values of ionizable groups in proteins by interfering with the natural environment of amino acid residues. Therefore, shifts in optimal $\mathrm{pH}$ value of enzymes due to the change in the solvent system can be seen.

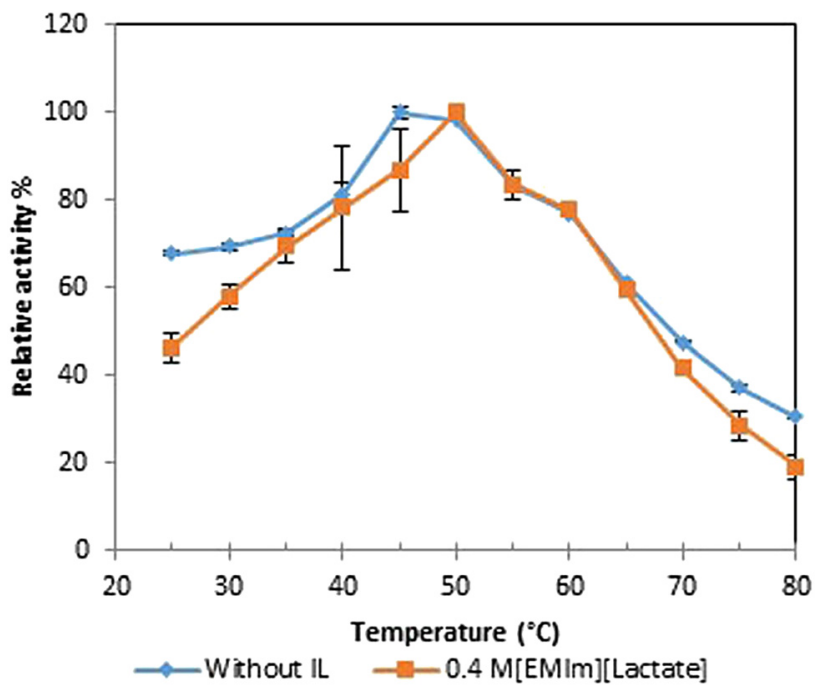

Figure 2: The activity of $\alpha$-amylase with and without [emim][Lac] at different temperatures from 25 to $80^{\circ} \mathrm{C}$.

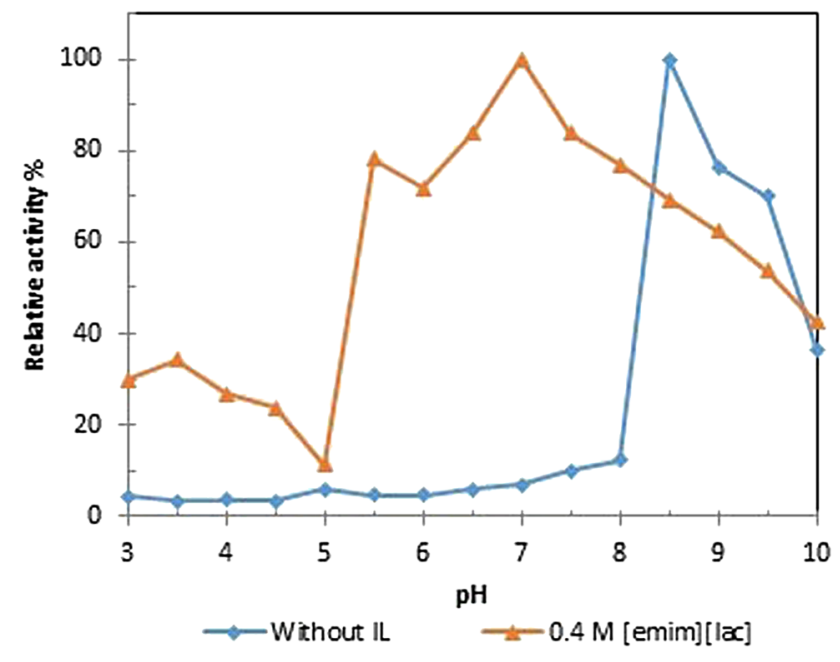

Figure 3: Relative activity of $\alpha$-amylase against $\mathrm{pH}$ in the absence and presence of [emim][lac].

\section{Thermal stability of a-amylase}

One of the major goals of the use of ILs as reaction media for enzymes is the improvement of the thermal stability of enzymes. This approach has advantages such as relatively low cost- and time-saving compared to other methods such as immobilization and genetic engineering. Using ILs to improve the thermal stability of enzyme is not always successful. Apart from the reports in the stabilization of enzymes, there are some observations of decrease in enzymes' thermal stability. Therefore, enzymes are not homogeneously stable in all types of ILs; the choice of correct IL is the most important factor [38]. In this study, thermal inactivation of $A$. oryzae $\alpha$-amylase at 40,50 , and $60{ }^{\circ} \mathrm{C}$ is determined by incubating enzyme solutions in the absence and presence of $0.4 \mathrm{M}$ of [emim] [lactate]. The $\alpha$-amylase activity assay was performed every $5 \mathrm{~min}$ for $20 \mathrm{~min}$ using an incubated enzyme solution. According to the results (Figure 4), activity of $\alpha$-amylase shows decrements in all temperatures in the absence and presence of [emim] [lactate]. Inactivation rates of $\alpha$-amylase in both conditions are quite similar at $40{ }^{\circ} \mathrm{C}$ and there is no significant difference at $50{ }^{\circ} \mathrm{C}$. The rate of inactivation at $60^{\circ} \mathrm{C}$ is obviously different in the absence and presence of [emim] [lactate]. In this temperature, $\alpha$-amylase in the presence of [emim] [lactate] loses its initial activity up to $80 \%$ after $20 \mathrm{~min}$, while in the absence of [emim][lactate], it just loses $40 \%$ of its initial activity in the same time. Similarity in the inactivation rates at 40 and $50^{\circ} \mathrm{C}$ may be related to the range of optimum temperature of the enzyme in the absence and presence of [emim][lactate]. Similar results are reported by other studies. Dabirmanesh reports a decrease in the activity and thermal 
stability of two related a-amylases from Bacillus amyloliquefaciens and Bacillus lichiniformis in the presence of [BMIm] [Cl] and [HMIm][Cl] [10]. Heller reports that thermal
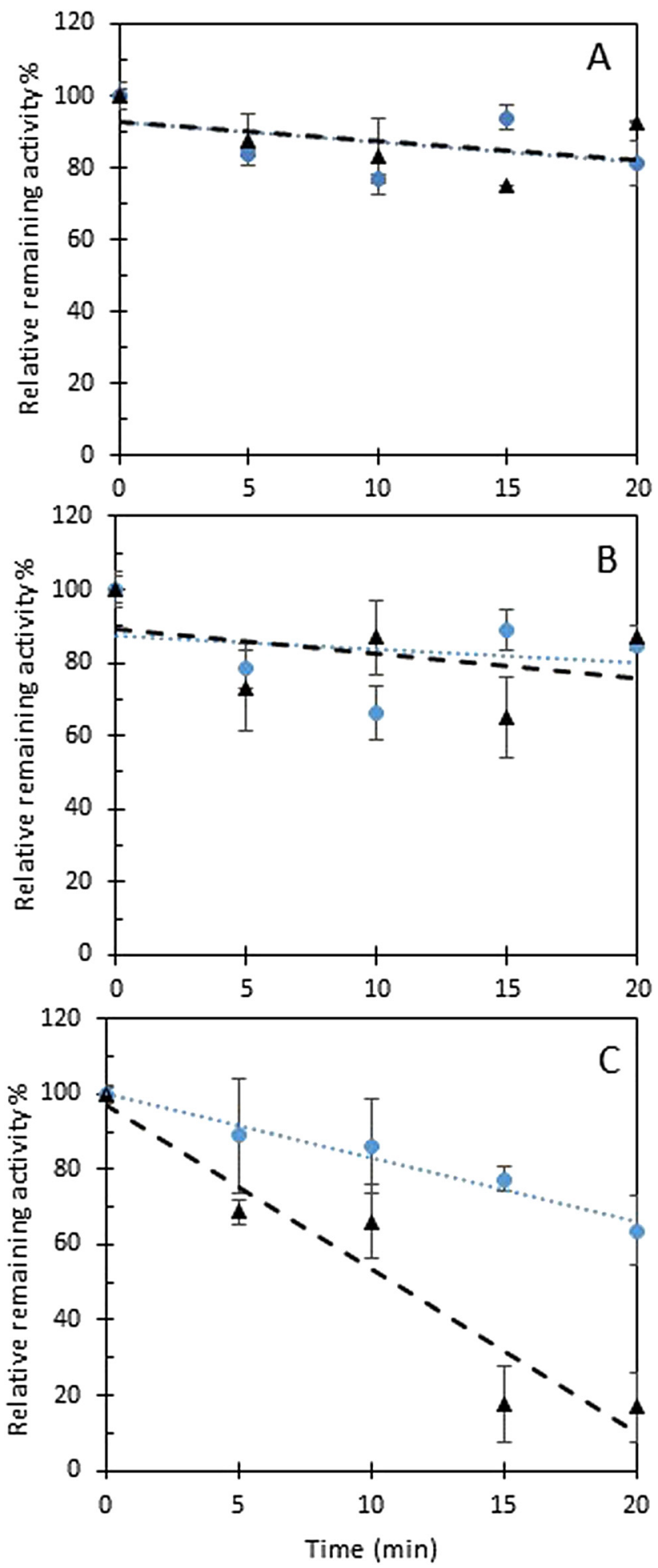

Figure 4: Percentage of relative remaining activity vs time plots to investigate thermal inactivation of $\alpha$-amylase in the absence $(\bullet)$ and presence ( $\Delta)$ of $0.4 \mathrm{M}$ of [emim] [Lac] at 40 (a), 50 (b) and $60^{\circ} \mathrm{C}(\mathrm{c})$. stability of green fluorescent protein (GFP) decreases in the presence of [bmim] [Cl] [39].

These results, alongside our results, show that ILs do not only increase the thermal stability of proteins but can also decrease their thermal stability.

\section{Intrinsic fluorescence spectroscopy}

Fluorescence spectroscopy is usually used to study folding/unfolding, substrate binding, and external quencher accessibility in proteins. One of the major advantages of using intrinsic fluorophores is that proteins are in their native state and there are no structural changes due to the addition of external fluorophores. Intrinsic fluorescence based on the Trp residue(s) is a simple and reliable method that is usually used for studying the folding/ unfolding states in proteins. The $\lambda_{\max }$ of Trp residue is quite sensitive to its local environment and the degree of exposure to solvent [40]. This technique is used in this study to investigate the structural transitions of $\alpha$-amylase due to its exposure to the different concentrations of [emim] [lactate]. Four concentrations $(0.2,0.4,0.6$, and $1 \mathrm{M})$ of [emim] [lactate] were used to acquire more information about the structural changes. The results of this experiment have been shown in Figure 5. As can be seen, $\alpha$-amylase exhibited the same $\lambda_{\max }$ in the absence and presence of [emim][lactate] but maximal fluorescence intensity $\left(I_{\max }\right)$

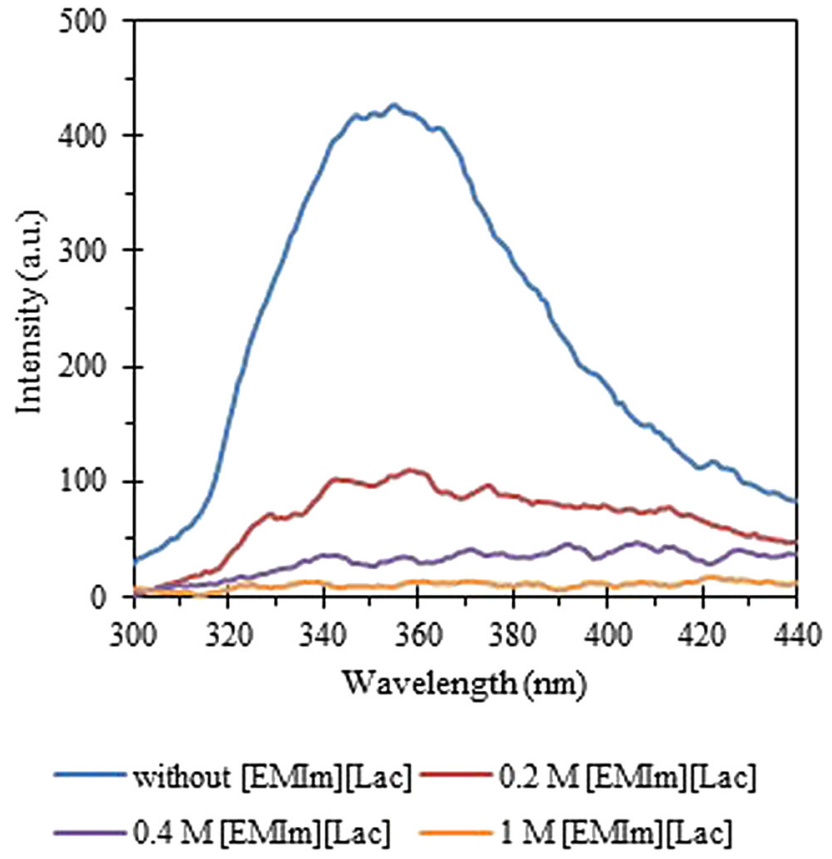

Figure 5: Intrinsic fluorescence analysis of $\alpha$-amylase in the absence and presence of different concentrations of [emim][Lac]. 
was drastically decreased when exposed to the [emim] [lactate]. Decrement in the $I_{\max }$ continued with increase in the concentration of [emim][lactate] and reached nearly zero in the presence of $1 \mathrm{M}$ of [emim][lactate]. Decrease in the $I_{\max }$ of Trp residue represents the unfolding of the structure of protein and exposure of Trp residues to the more polar environment. This evidence reveals the reason of the decrease in the activity of the $\alpha$-amylase accompanied by the increase in the concentration of [emim][lactate] (Figure 1). The EMIm cations interact with lactate anions and generate a network of interactions that is similar to that of the three-dimensional network of interactions between water molecules. Lactate anion has great hydrogen bond capacity and hence a greater basicity and stronger nucleophilicity. These properties interfere with internal hydrogen bonds and interactions with the positively charged sites in $\alpha$-amylase; therefore, the $\alpha$-amylase conformation changes to the unfolded state.

\section{Conclusion}

According to the results, addition of [emim][lactate] as cosolvent can affect $A$. oryzae $\alpha$-amylase activity and stability. Imidazolium based ILs may increase the solubility of starch and hence activity of $\alpha$-amylase should be increased. But our results demonstrated that both activity and stability of $\alpha$-amylase decreased in presence of [emim][lactate]. The intrinsic fluorescence spectroscopy analysis revealed that $\alpha$-amylase unfolds with addition of [emim][lactate]. The structural unfolding of $\alpha$-amylase is directly dependent to the concentration of [emim][lactate] concentrations. In conclusion, these unfolding steps are the most important reason for loss in activity and thermal stability and increase in $\mathrm{Km}$ of $\alpha$-amylase in the presence of [emim][lactate].

Acknowledgment: We would like to appreciate the Science and Research Branch of Islamic Azad University for the supports.

Research funding: None declared.

Author contributions: All authors have accepted responsibility for the entire content of this manuscript and approved its submission.

Competing interests: Authors state no conflict of interest.

\section{References}

1. Pranay K, Padmadeo S, Jha V, Prasad B. Screening and identification of amylase producing strains of Bacillus. J Appl Biol Biotechnol 2019;7:57-62.
2. Gupta R, Gigras P, Mohapatra H, Goswami VK, Chauhan B. Microbial $\alpha$-amylases: a biotechnological perspective. Process Biochem 2003;38:1599-616.

3. Dumorne K, Cordova DC, Astorga-Elo M, Renganathan P. Extremozymes: a potential source for industrial applications. J Microbiol Biotechnol 2017;27:649-59.

4. Xu Q, Kennedy JF, Liu L. An ionic liquid as reaction media in the ring opening graft polymerization of $\varepsilon$-caprolactone onto starch granules. Carbohydr Polym 2008;72:113-21.

5. Reddy NS, Nimmagadda A, Rao KRSS. An overview of the microbial $\alpha$-amylase family. Afr J Biotechnol 2003;2:780-7.

6. Stepankova V, Khabiri M, Brezovsky J, Pavelka A, Sykora J, Amaro $M$, et al. Expansion of access tunnels and active-site cavities influence activity of haloalkane dehalogenases in organic cosolvents. Chem Bio Chem 2013;14:890-7.

7. Yang Z. Natural deep eutectic solvents and their applications in biotechnology. In: Application of ionic liquids in biotechnology. Berlin: Springer; 2018: pp. 31-59.

8. Lei Z, Chen B, Koo Y-M, MacFarlane DR. Introduction: ionic liquids. Chem Rev 2017;117:6633-5.

9. Vekariya RL. A review of ionic liquids: applications towards catalytic organic transformations. J Mol Liq 2017;227:44.

10. Dabirmanesh B, Daneshjou S, Sepahi AA, Ranjbar B, KhavariNejad RA, Gill P, et al. Effect of ionic liquids on the structure, stability and activity of two related $\alpha$-amylases. Int J Biol Macromol 2011;48:93-7.

11. van Rantwijk F, Sheldon RA. Biocatalysis in ionic liquids. Chem Rev 2007;107:2757-85.

12. Egorova KS, Gordeev EG, Ananikov VP. Biological activity of ionic liquids and their application in pharmaceutics and medicine. Chem Rev 2017;117:7132-89.

13. D’Oronzo E, Secundo F, Minofar B, Kulik N, Pometun AA, Tishkov Vl. Activation/inactivation role of ionic liquids on formate dehydrogenase from Pseudomonas sp. 101 and its mutated thermostable form. ChemCatChem 2018;10:3247-59.

14. Welton T. Ionic liquids: a brief history. Biophys Rev 2018;10: 691-706.

15. Zhao H. Protein stabilization and enzyme activation in ionic liquids: specific ion effects. J Chem Technol Biotechnol 2016;91:25-50.

16. Khabiri M, Minofar B, Brezovský J, Damborský J, Ettrich R. Interaction of organic solvents with protein structures at proteinsolvent interface. J Mol Model 2013;19:4701-11.

17. Zhao H, Campbell S, Solomon J, Song Z-Y, Olubajo O. Improving the enzyme catalytic efficiency using ionic liquids with kosmotropic anions. Chin J Chem 2006;24:580-4.

18. Pinto AC, Lapis AAM, da Silva BV, Bastos RS, Dupont J, Neto BAD. Pronounced ionic liquid effect in the synthesis of biologically active isatin-3-oxime derivatives under acid catalysis. Tetrahedron Lett 2008;49:5639-41.

19. Musa MM, Ziegelmann-Fjeld KI, Vieille C, Phillips RS. Activity and selectivity of W110A secondary alcohol dehydrogenase from Thermoanaerobacter ethanolicus in organic solvents and ionic liquids: mono- and biphasic media. Org Biomol Chem 2008;6: 887-92.

20. Sgalla S, Fabrizi G, Cacchi S, Macone A, Bonamore A, Boffi A. Horseradish peroxidase in ionic liquids. J Mol Catal B Enzym 2007;44:144-8.

21. Zhao H, Jackson L, Song Z, Olubajo O. Enhancing protease enantioselectivity by ionic liquids based on chiral- or $\omega$-amino acids. Tetrahedron Asymmetry 2006;17:1549-53. 
22. Ventura SPM, Santos LDF, Saraiva JA, Coutinho JAP. Concentration effect of hydrophilic ionic liquids on the enzymatic activity of Candida antarctica lipase B. World J Microbiol Biotechnol 2012;28:2303-10.

23. Jiang Y, Guo C, Xia H, Mahmood I, Liu C, Liu H. Enzymatic magnetic nanoparticles supported ionic liquids for lipase immobilization: enzyme activity in catalyzing esterification. J Mol Catal B 2009; 58:103-9.

24. Ebrahimi M, Hosseinkhani S, Heydari A, Khavari-Nejad RA, Akbari J. Controversial effect of two methylguanidine-based ionic liquids on firefly luciferase. Photochem Photobiol Sci 2012;11:828.

25. Ebrahimi M, Hosseinkhani S, Heydari A, Khavari-Nejad RA, Akbari J. Improvement of thermostability and activity of firefly luciferase through [TMG][Ac] ionic liquid mediator. Appl Biochem Biotechnol 2012;168:604-15.

26. Naushad M, Alothman ZA, Khan AB, Ali M. Effect of ionic liquid on activity, stability, and structure of enzymes: a review. Int J Biol Macromol 2012;51:555-60.

27. Zhao H, Olubajo O, Song Z, Sims AL, Person TE, Lawal RA, et al. Effect of kosmotropicity of ionic liquids on the enzyme stability in aqueous solutions. Bioorg Chem 2006;34:15-25.

28. Yang Z, Yue YJ, Huang WC, Zhuang XM, Chen ZT, Xing M. Importance of the ionic nature of ionic liquids in affecting enzyme performance. J Biochem 2009;145:355-64.

29. Sate D, Janssen MHA, Stephens G, Sheldon RA, Seddon KR, Lu JR. Enzyme aggregation in ionic liquids studied by dynamic light scattering and small angle neutron scattering. Green Chem 2007; 9:859.

30. Turner MB, Spear SK, Huddleston JG, Holbrey JD, Rogers RD. Ionic liquid salt-induced inactivation and unfolding of cellulase from Trichoderma reesei. Green Chem 2003;5:443.
31. Ebrahimi M, Hosseinkhani S, Heydari A, Khavari-Nejad RA, Akbari J. Controversial effect of two methylguanidine-based ionic liquids on firefly luciferase. Photochem Photobiol Sci 2012;11:828-34.

32. Yang Z, Pan W. Ionic liquids: green solvents for nonaqueous biocatalysis. Enzym Microb Technol 2005;37:19-28.

33. Gao WW, Zhang FX, Zhang GX, Zhou CH. Key factors affecting the activity and stability of enzymes in ionic liquids and novel applications in biocatalysis. Biochem Eng J 2015;99: 67-84.

34. Tavares APM, Rodriguez O, Macedo EA. Peroxidase biocatalysis in water-soluble ionic liquids: activity, kinetic and thermal stability. Biocatal Biotransform 2012;30:417-25.

35. Ahmad E, Rabbani G, Zaidi N, Ahmad B, Khan RH. Pollutantinduced modulation in conformation and $\beta$-lactamase activity of human serum Albumin. PLoS One 2012;7. https://doi.org/10. 1371/journal.pone.0038372.

36. Tipton KF, Dixon H. Effects of pH on enzymes 1979;63:183-234.

37. Pace CN, Grimsley GR, Scholtz JM. Protein ionizable groups: $\mathrm{pK}$ values and their contribution to protein stability and solubility. J Biol Chem 2009;284:13285-9. PMID: 19164280.

38. Patel R, Kumari M, Khan AB. Recent advances in the applications of ionic liquids in protein stability and activity: a review. Appl Biochem Biotechnol 2014;172:3701-20.

39. Heller WT, O'Neill HM, Zhang Q, Baker GA. Characterization of the influence of the ionic liquid 1-butyl-

3-methylimidazolium chloride on the structure and thermal stability of green fluorescent protein. J Phys Chem B 2010; 114:13866-71.

40. Lakowicz JR. Principles of fluorescence spectroscopy. Berlin: Springer Science \& Business Media; 2013. 